\title{
28 Research Suare \\ Enhancement and Modeling of Drain Current in Negative Capacitance Double Gate TFET
}

\section{SHIKHA U S ( $\nabla$ shikhasachin@cusat.ac.in )}

Cochin University of Science and Technology School of Engineering https://orcid.org/0000-0003-16164483

\section{Rekha K James}

Cochin University of Science and Technology

Jobymol Jacob

CEP: College of Engineering Poonjar

\section{Anju Pradeep}

CUSAT: Cochin University of Science and Technology

\section{Research Article}

Keywords: Negative capacitance, Tunnel Field Effect, Transistors, Drain current modeling, Double Gate structure, Heterojunction, Tangent line approximation

Posted Date: March 11th, 2021

DOl: https://doi.org/10.21203/rs.3.rs-271741/v1

License: (c) (i) This work is licensed under a Creative Commons Attribution 4.0 International License. Read Full License 


\section{Abstract}

The drain current improvement in a Negative Capacitance Double Gate Tunnel Field Effect Transistor (NCDG TFET) with the help of Heterojunction $(\mathrm{HJ})$ at the source-channel region is proposed and modeled in this paper. The gate oxide of the proposed TFET is a stacked configuration of high-k over low-k to improve the gate control without any lattice mismatches. Tangent Line Approximation (TLA) method is used here to model the drain current accurately. The model is validated by incorporating two dimensional simulation of DG-HJ TFET with one dimensional Landau-Khalatnikov (LK) equation. The model matches excellently with the device simulation results. The impact of stacked gate oxide topology is also studied in this paper by comparing the characteristics with unstacked gate oxide. Voltage amplification factor (Av), which is an important parameter in NC devices is also analyzed.

\section{Full Text}

Due to technical limitations, full-text HTML conversion of this manuscript could not be completed. However, the latest manuscript can be downloaded and accessed as a PDF.

\section{Figures}

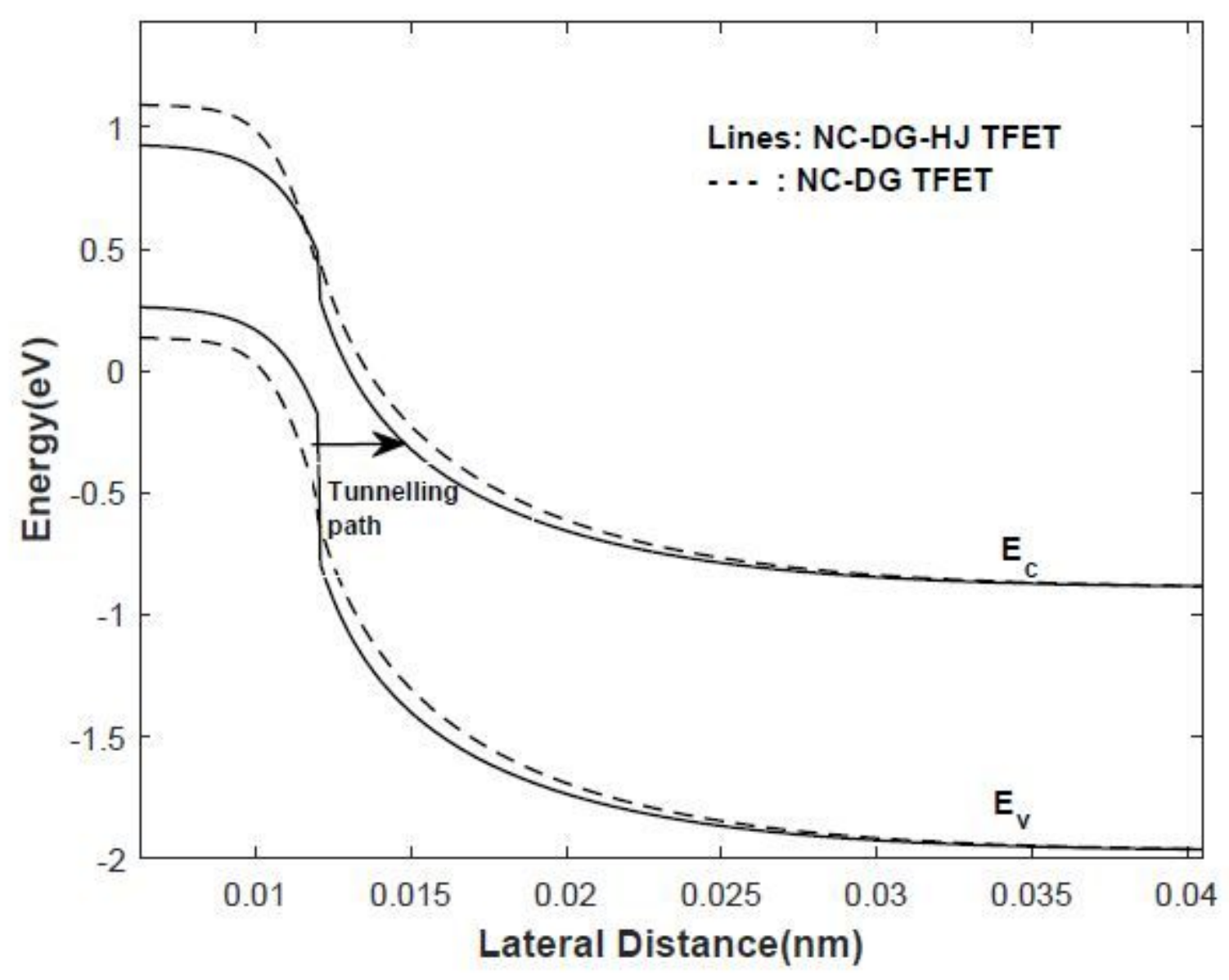


Figure 1

Band diagram of NC homojunction and heterojunc- tion DG TFET

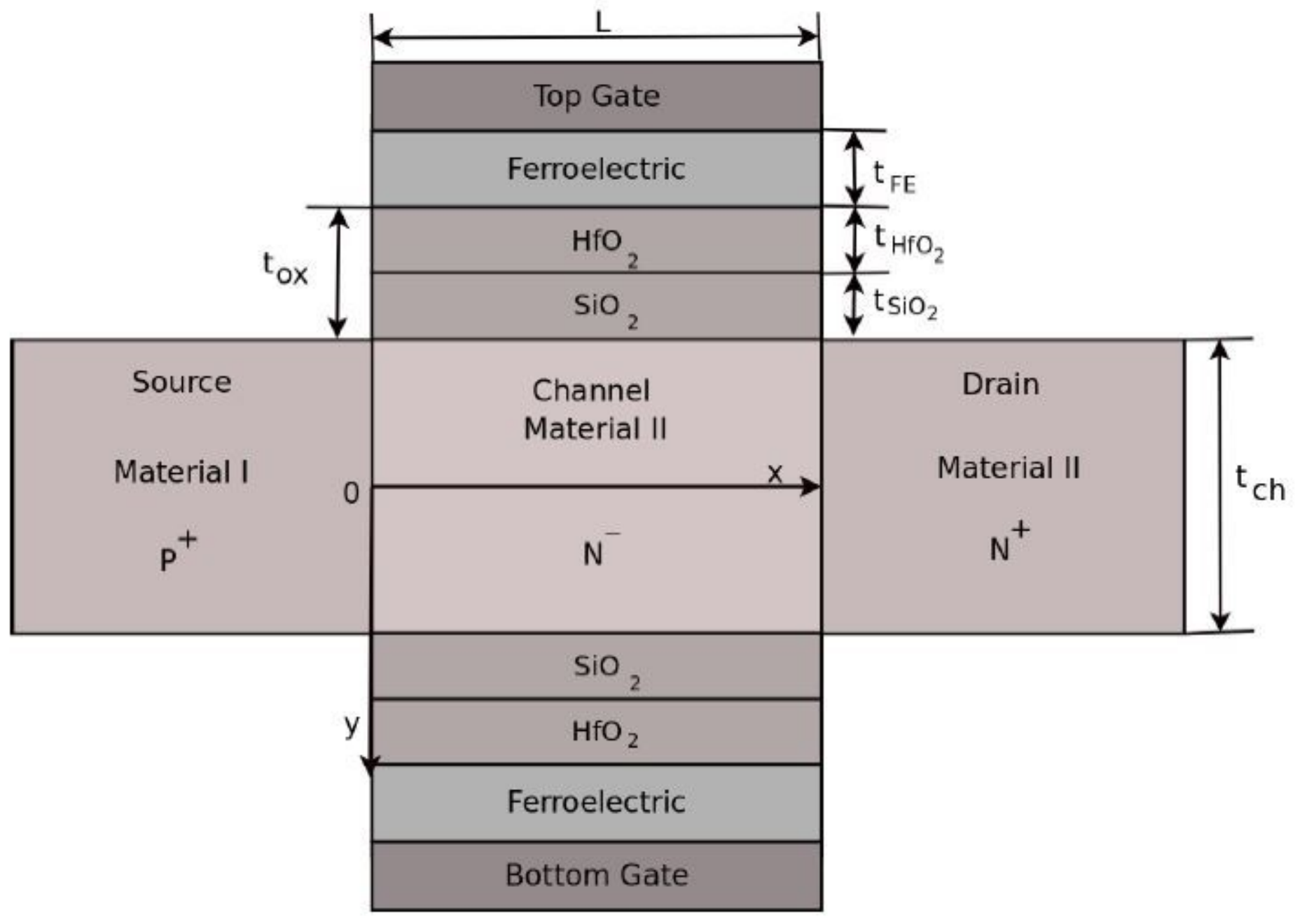

Figure 2

Cross sectional view of NC-DG-HJ TFET 


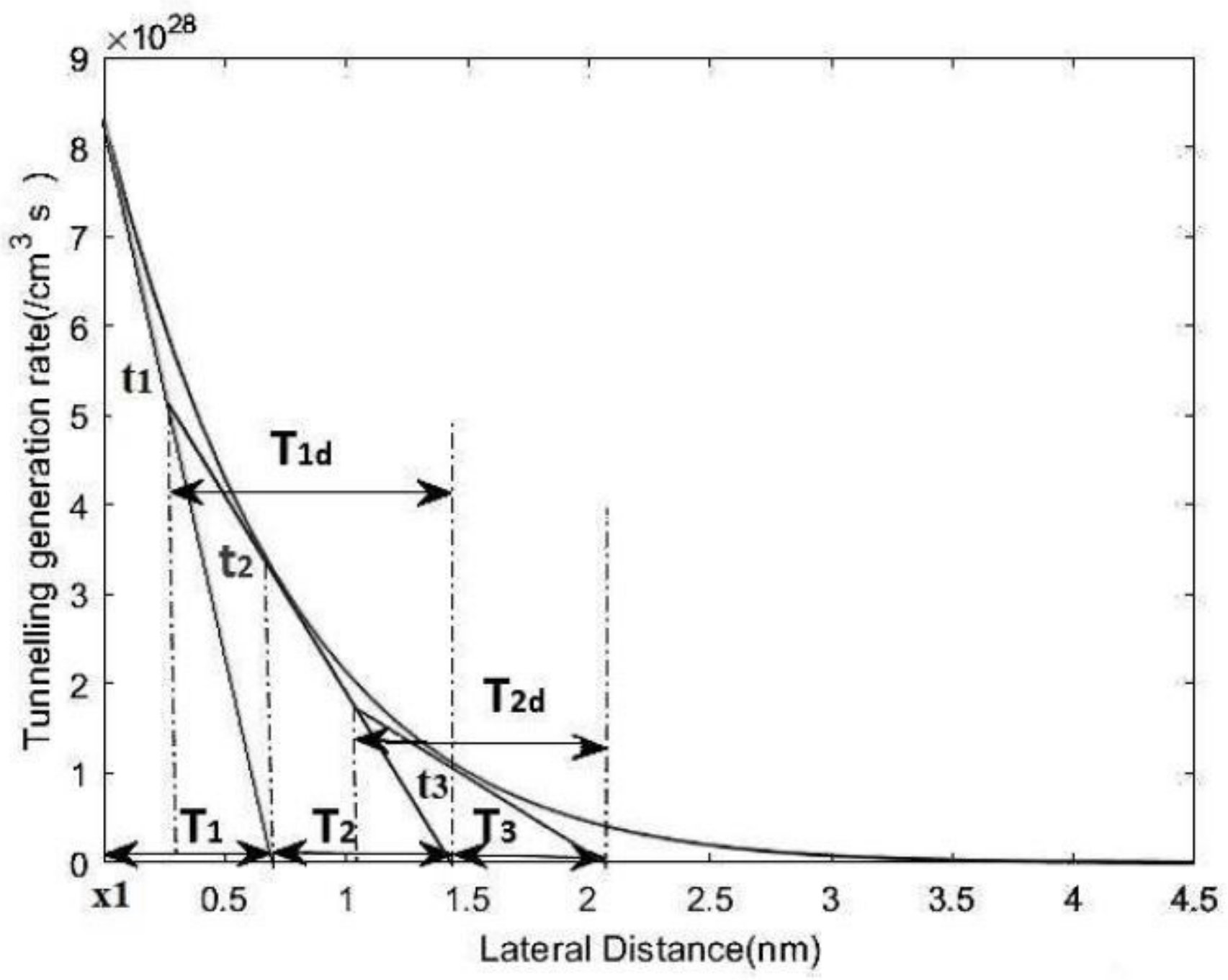

Figure 3

Tunneling generation rate along the channel depicting TLA method [8] 


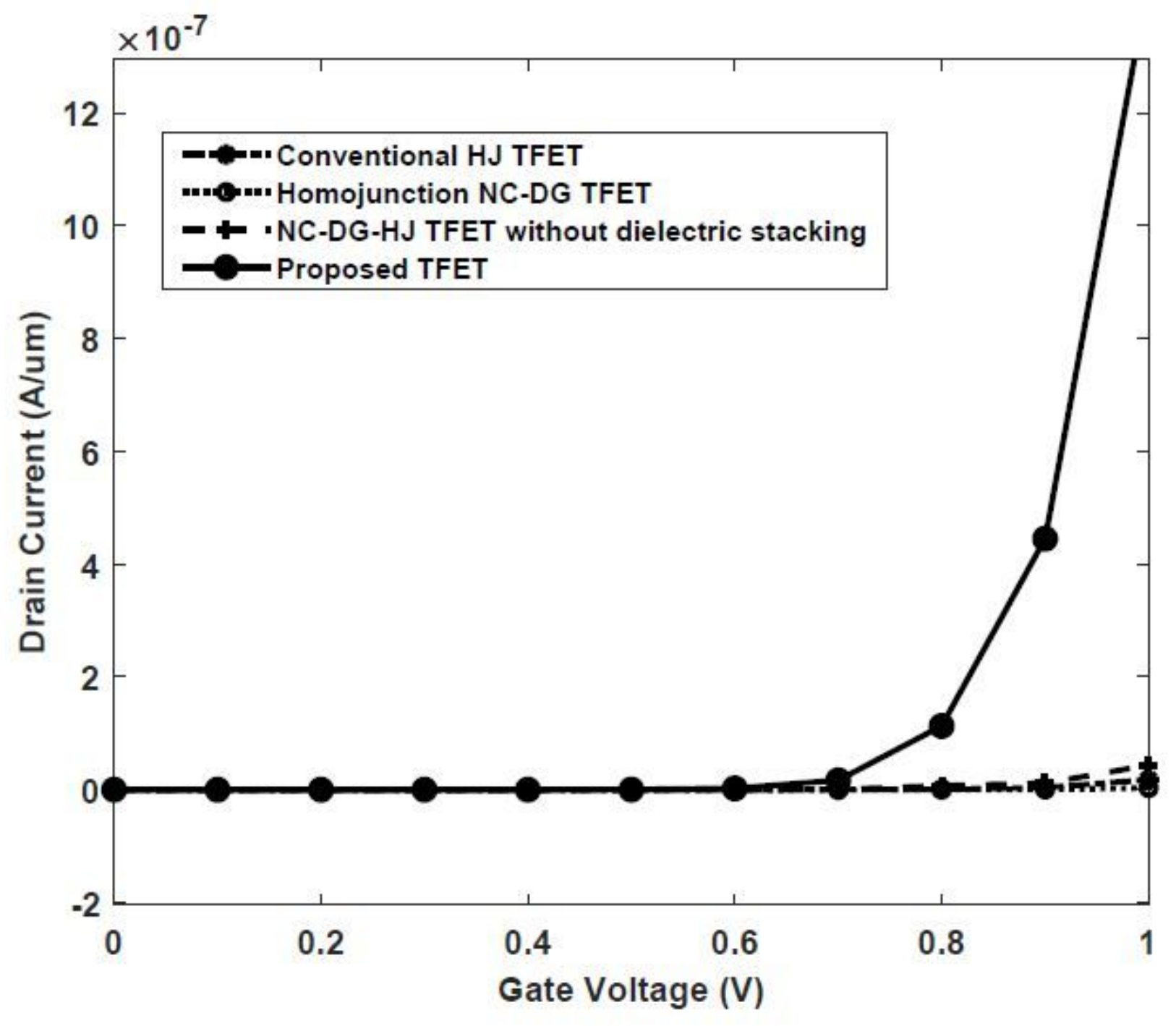

Figure 4

Transfer characteristics in linear scale for hetero- junction TFET, homojunction NC-DG TFET, heterojunction NC-DG-TFET and heterojunction NC-DG TFET with dielectric stacking(proposed) at VDS=1V 


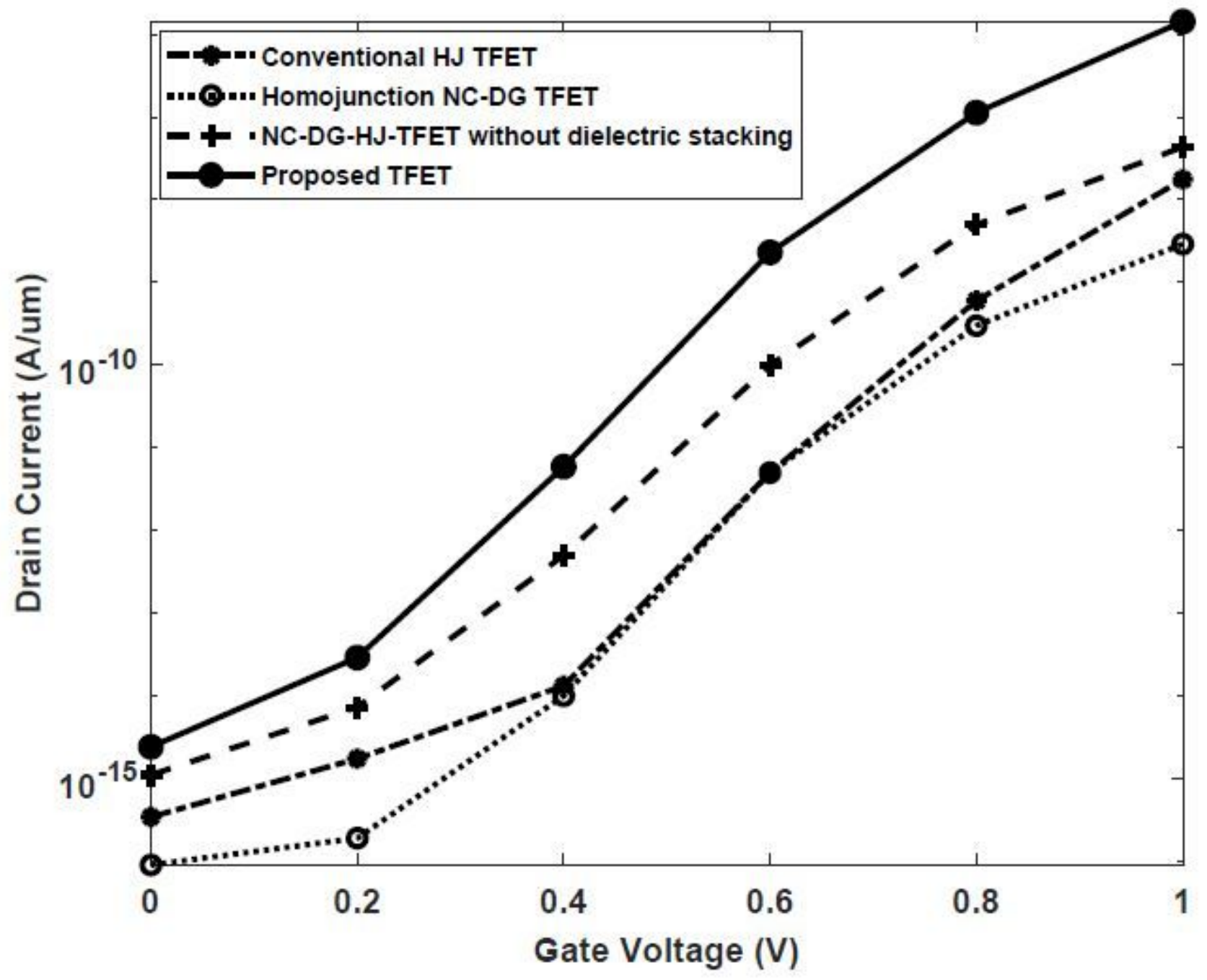

Figure 5

Transfer characteristics in logarithmic scale for het- erojunction TFET, homojunction NC-DG TFET, heterojunction NC-DG-TFET and heterojunction NC-DG TFET with dielectric stacking(proposed) at VDS=1V 


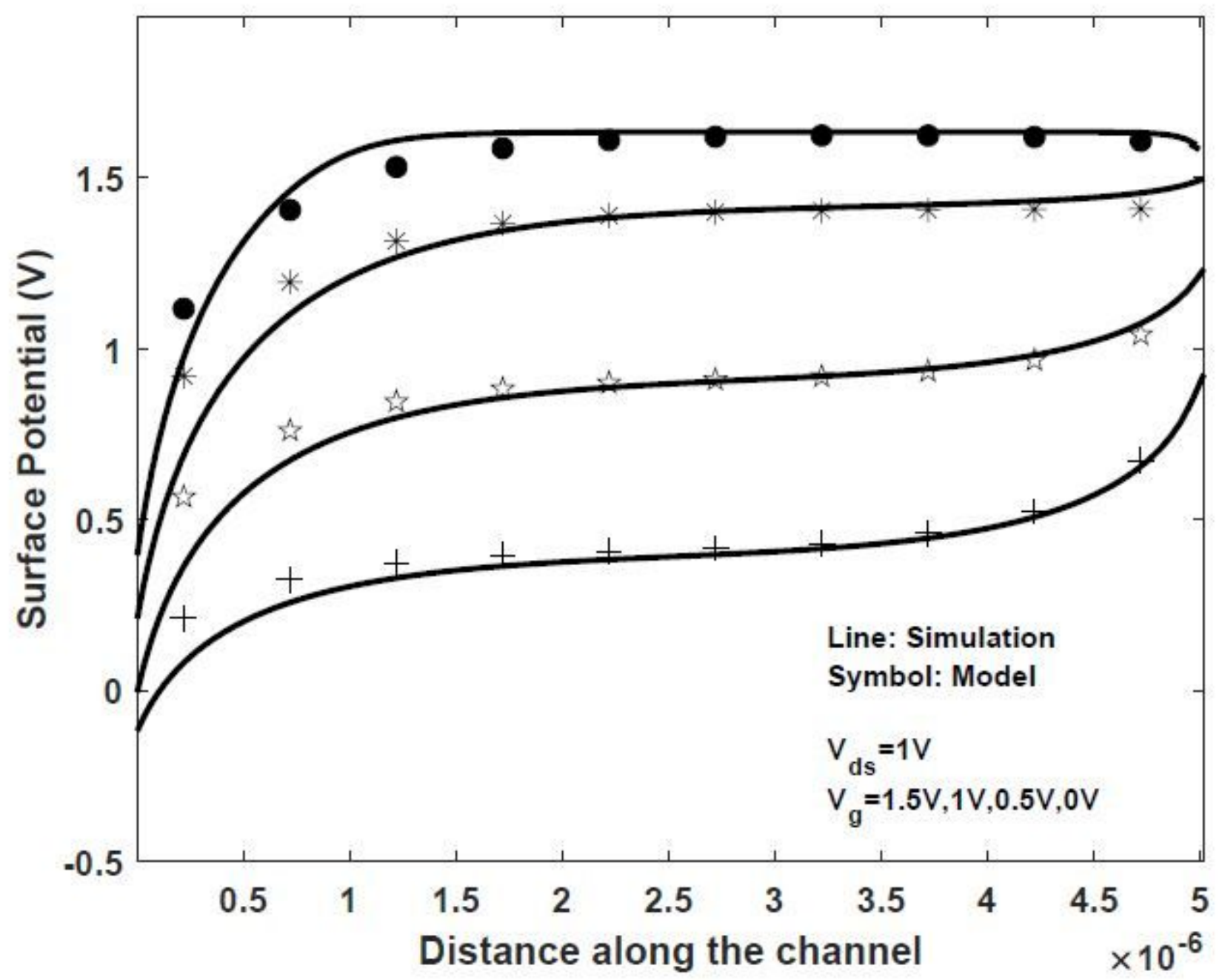

Figure 6

Surface potential distribution for NC-DG-HJ TFET for VDS=1V and varying VG 


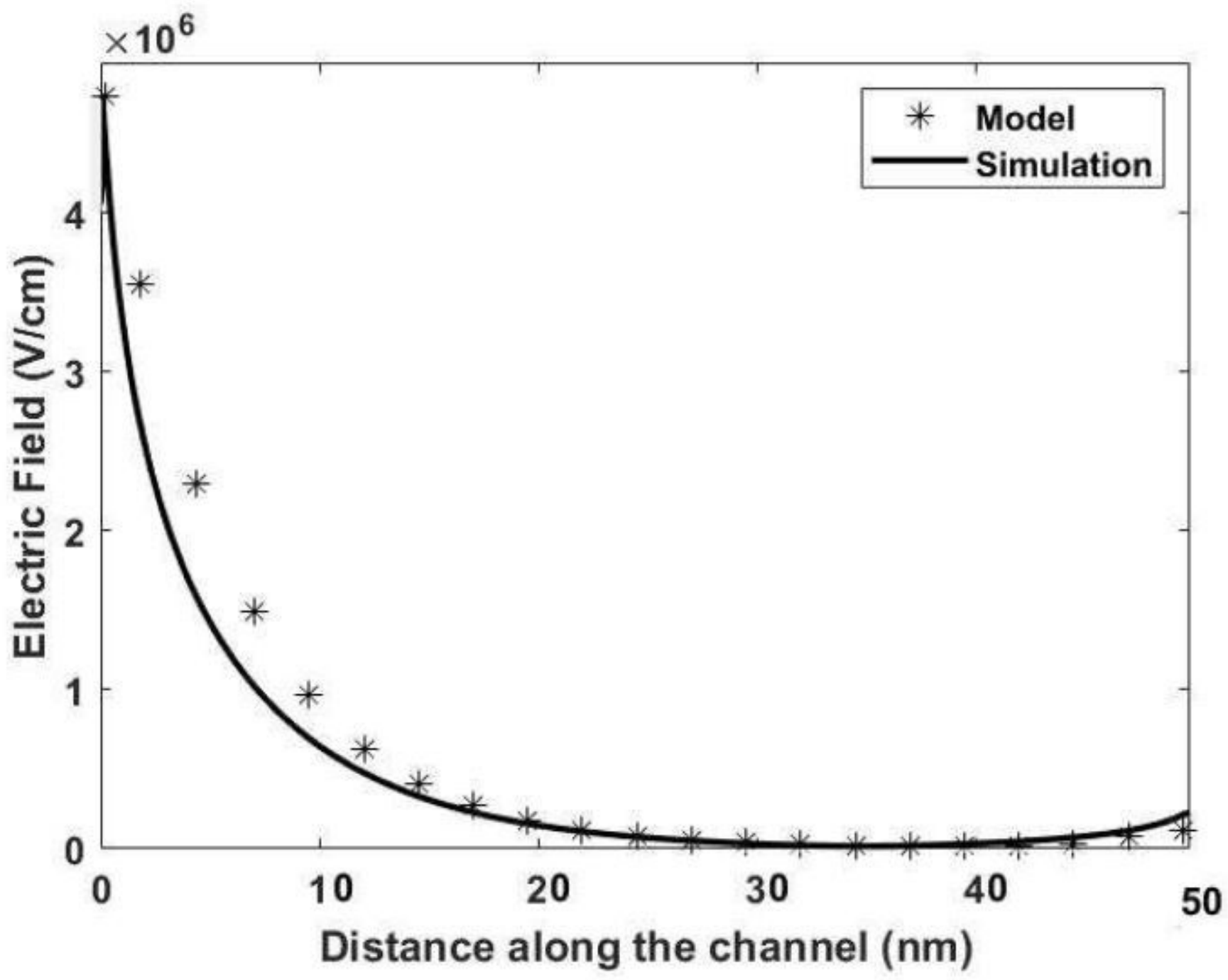

Figure 7

Electric eld distribution of Proposed NC TFET for VDS=VG=1V 


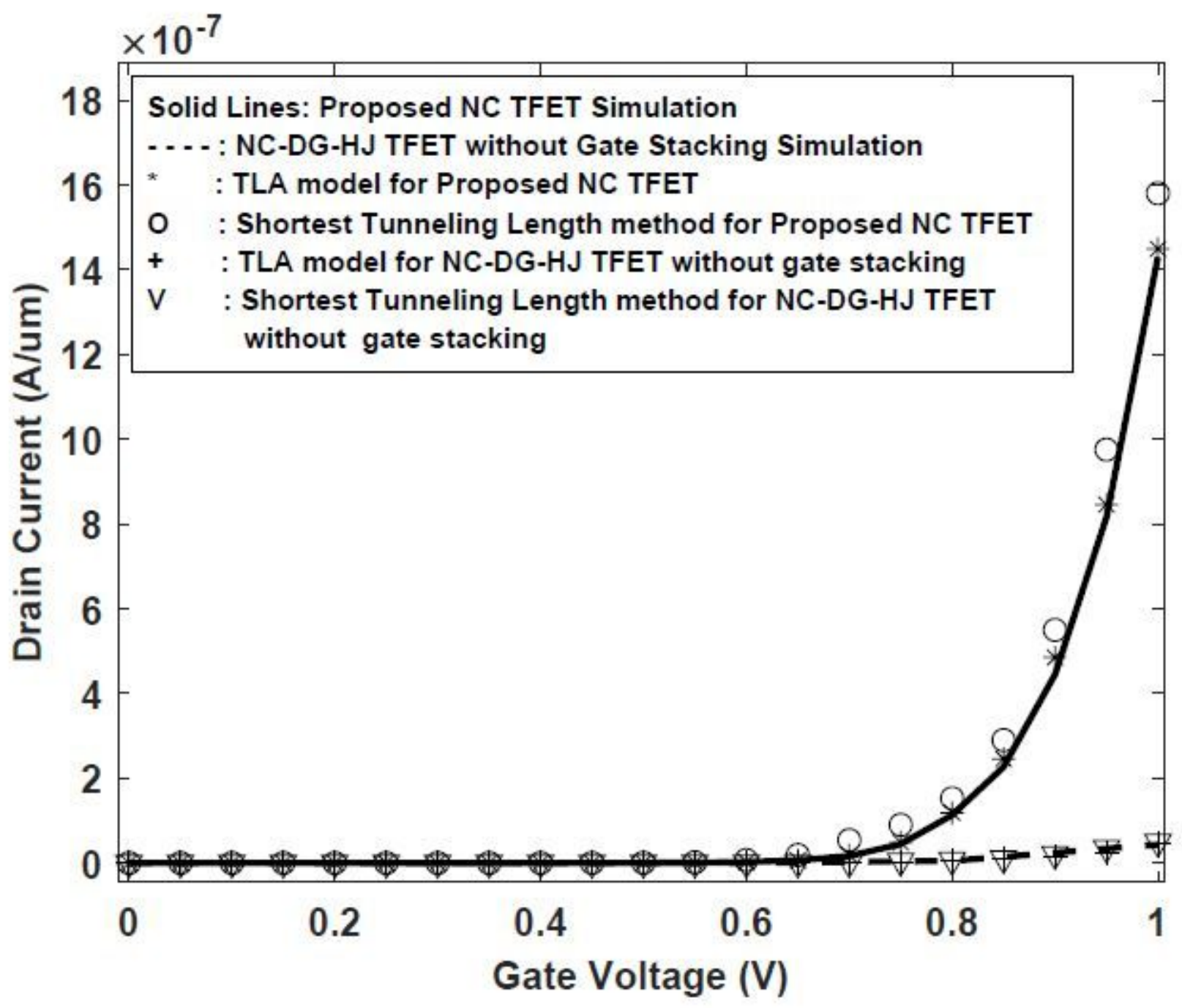

Figure 8

Comparison of simulation results of transfer charac- teristics in linear scale for Proposed NC TFET and NC TFET without gate stacking with respective models based on TLA and Shortest Tunneling Length method at VDS $=1 \mathrm{~V}$ 


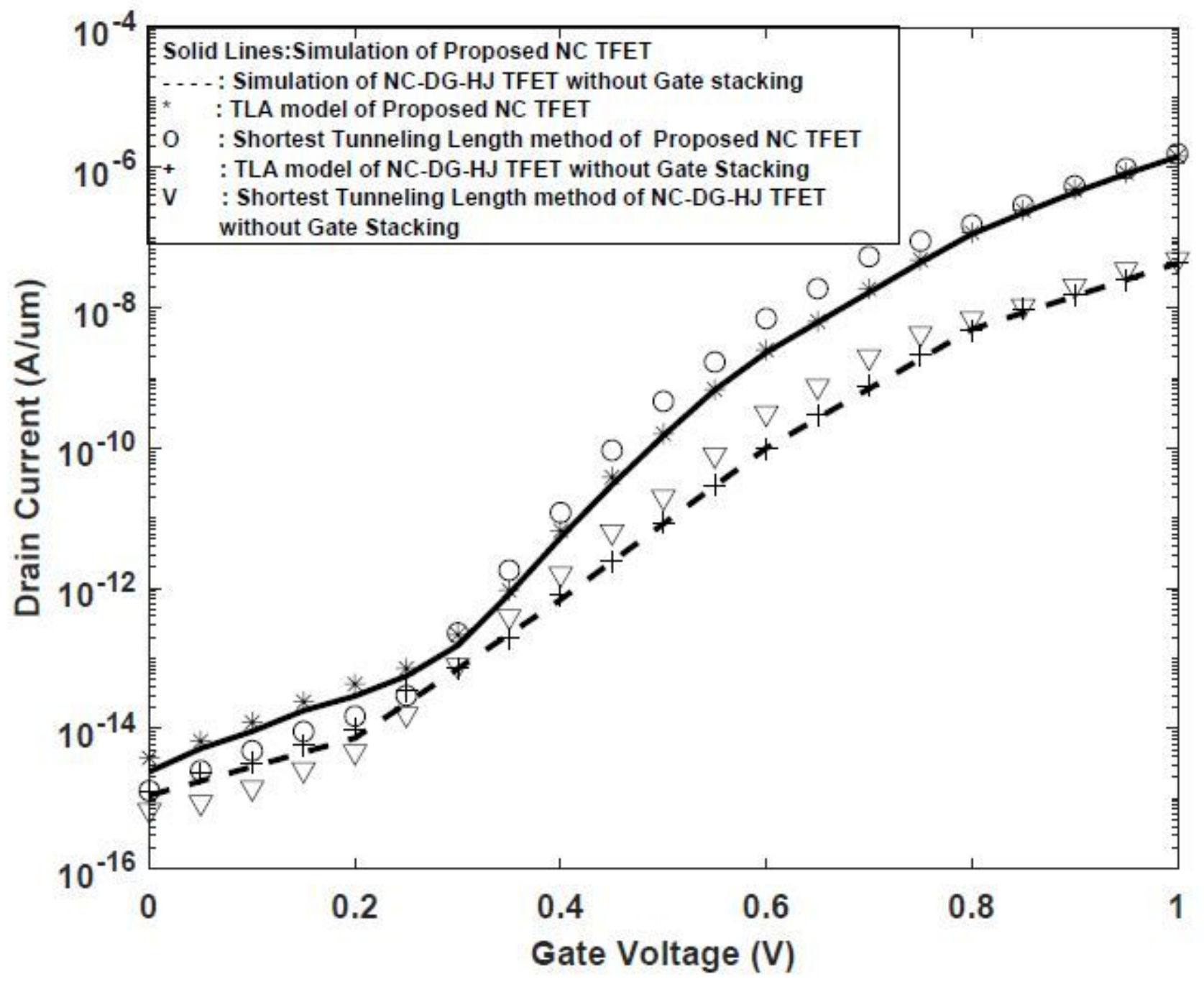

Figure 9

Comparison of simulation results of transfer charac- teristics in logarithmic scale for Proposed NC TFET and NC TFET without gate stacking with respective models based on TLA and Shortest Tunneling Length method at VDS $=1 \mathrm{~V}$ 


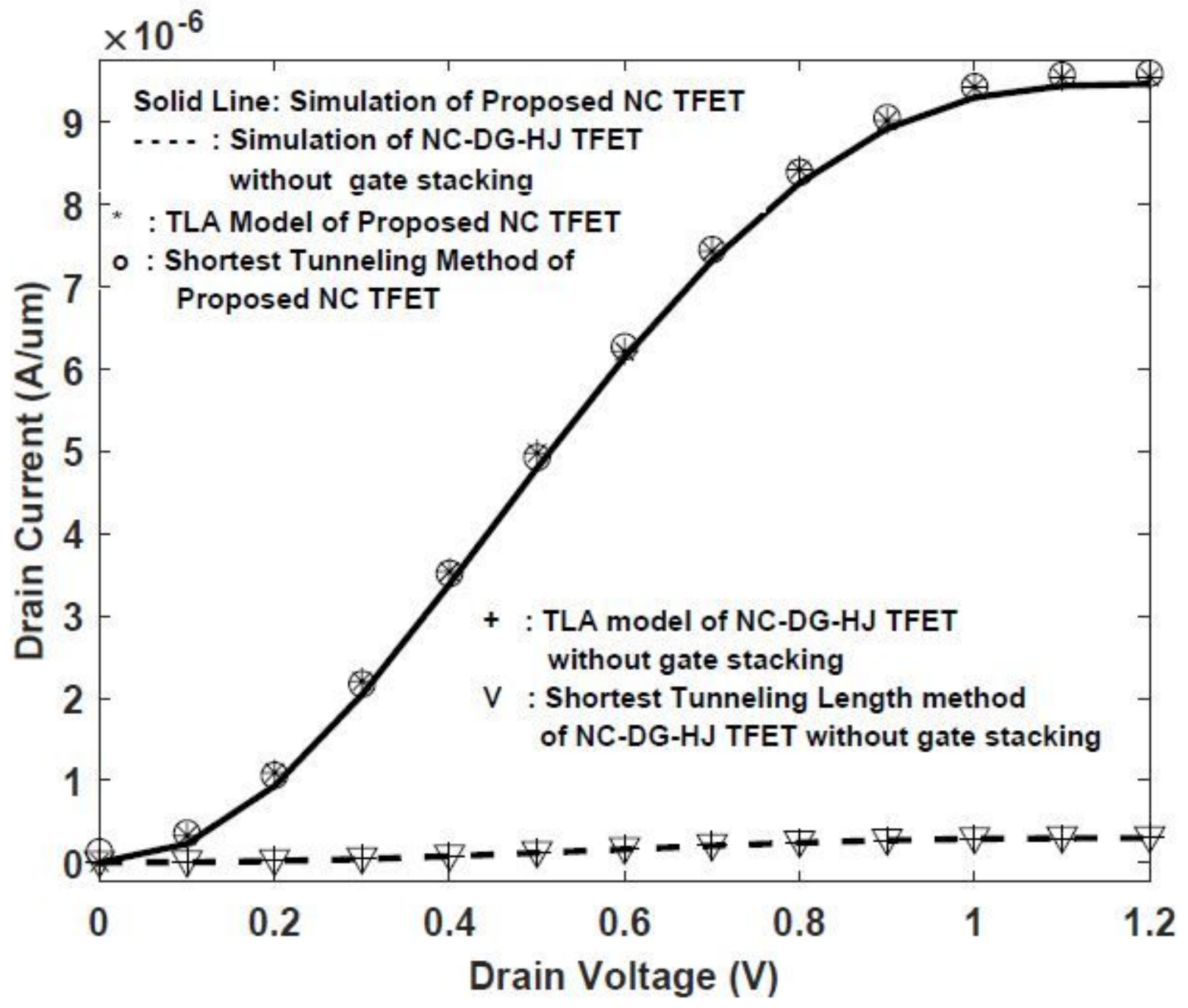

Figure 10

Comparison of simulation results of output charac- teristics of Proposed NC TFET and NC TFET without gate stacking with respective models based on TLA and Shortest Tunneling Length method at VG $=1.2 \mathrm{~V}$ 


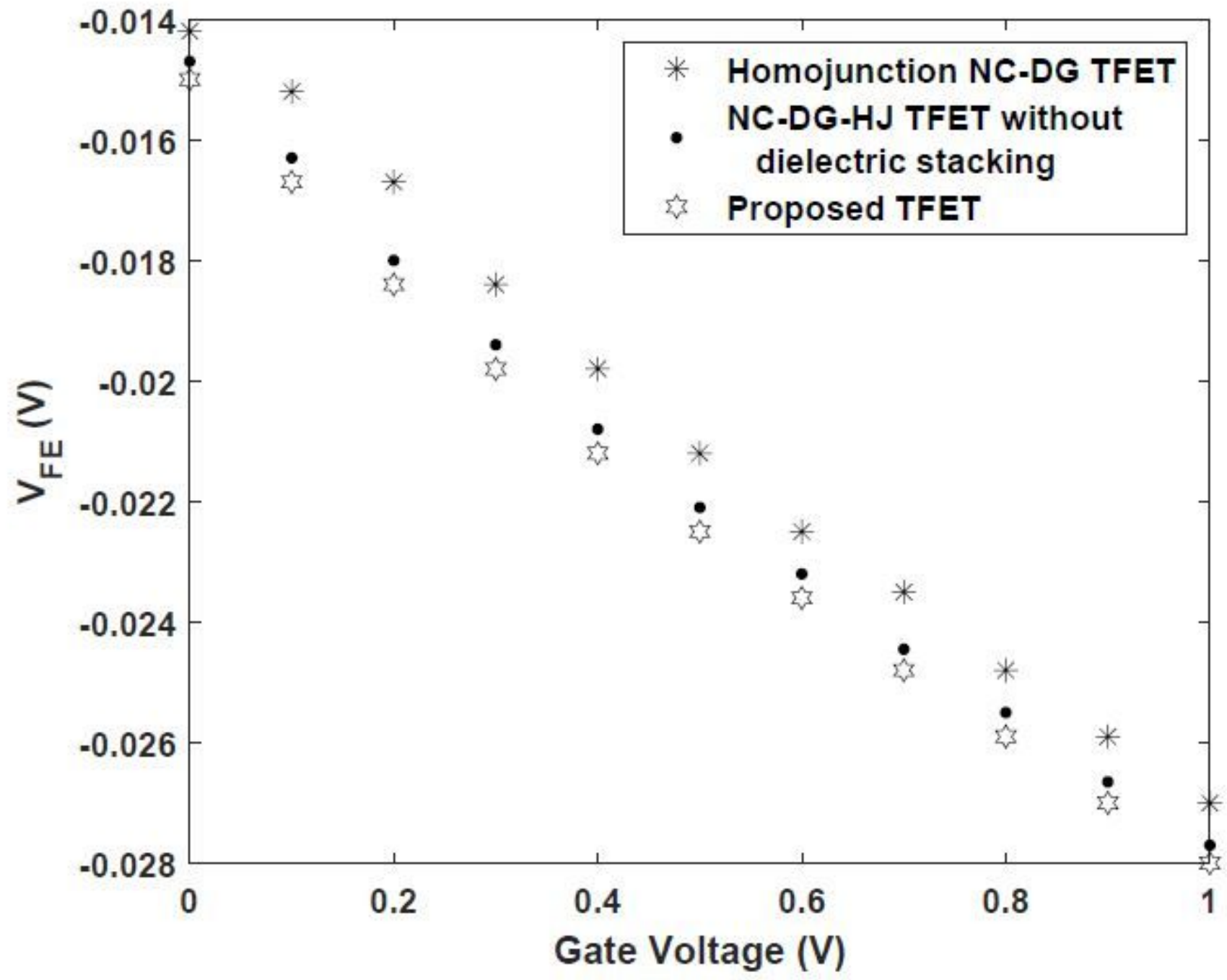

Figure 11

Plot of VFE versus VG for VDS $=1 \mathrm{~V}$ 


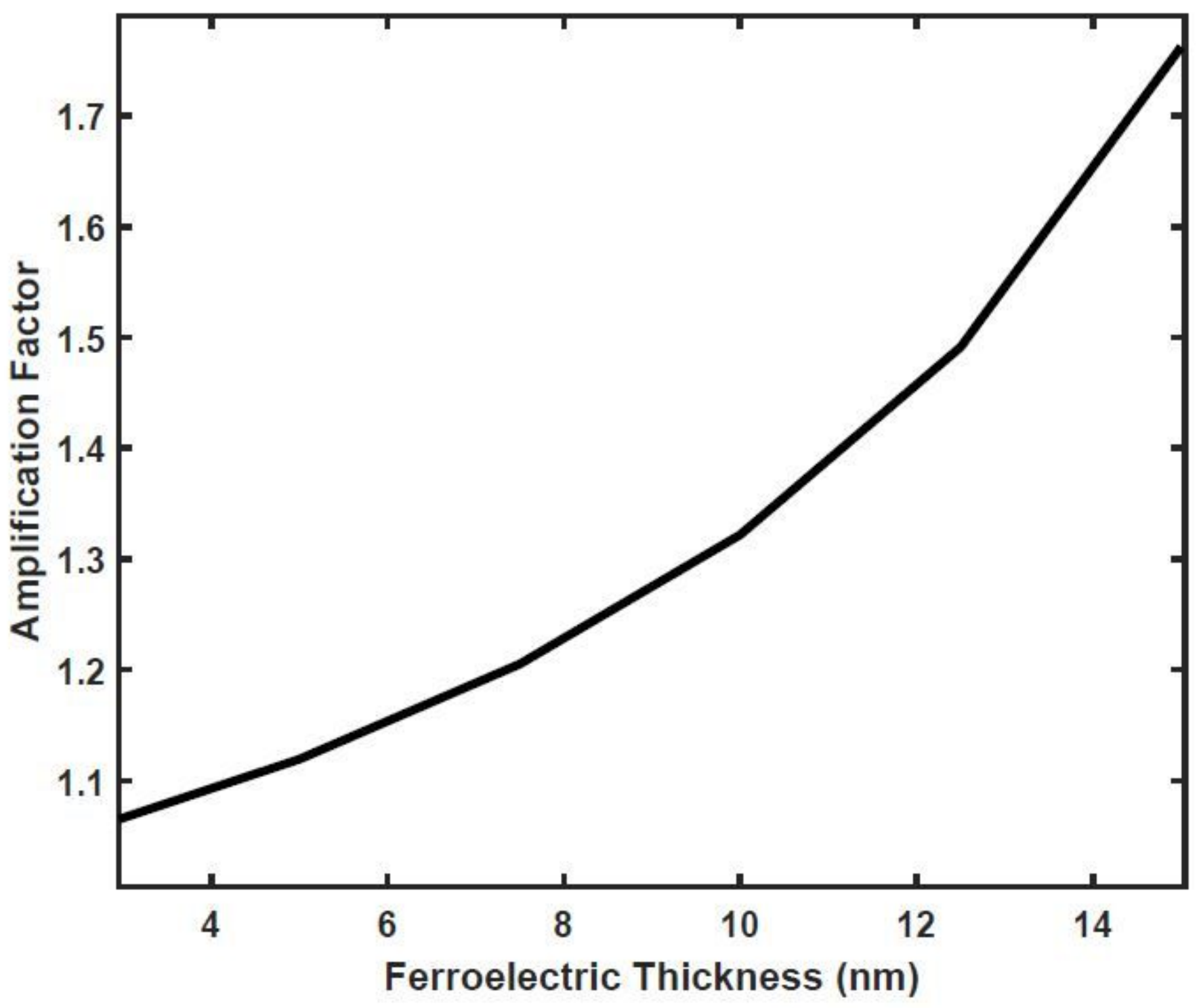

Figure 12

Effect of FE thickness on Avfor the proposed NC- DG-HJ TFET 